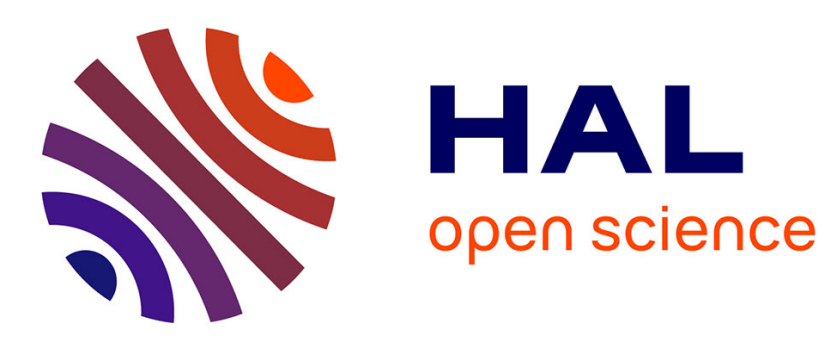

\title{
Pedir las Indias. Las cartas indipetae de los jesuitas europeos, siglos XVI-XVIII, ensayo historiográfico
}

\author{
Aliocha Maldavsky
}

\section{To cite this version:}

Aliocha Maldavsky. Pedir las Indias. Las cartas indipetae de los jesuitas europeos, siglos XVI-XVIII, ensayo historiográfico. Relaciones, 2012, 132 (33), pp.147-181. hal-01402522

HAL Id: hal-01402522

https://hal.parisnanterre.fr/hal-01402522

Submitted on 4 Jan 2018

HAL is a multi-disciplinary open access archive for the deposit and dissemination of scientific research documents, whether they are published or not. The documents may come from teaching and research institutions in France or abroad, or from public or private research centers.
L'archive ouverte pluridisciplinaire HAL, est destinée au dépôt et à la diffusion de documents scientifiques de niveau recherche, publiés ou non, émanant des établissements d'enseignement et de recherche français ou étrangers, des laboratoires publics ou privés. 


\title{
Pedir las Indias. Las cartas indipetae de los jesuitas europeos, siglos XVI-XVIII, ensayo historiográfico
}

\author{
Aliocha Maldavsky* \\ UNIVERSIDAD PARIS OUEST NANTERRE LA DÉFENSE
}

Este artículo presenta una síntesis historiográfica acerca de las cartas indipetae, conservadas en el archivo romano de la Compañía de Jesús. Del estudio de estas cartas, escritas al general de la Compañía de Jesús por jesuitas de Europa, muchas veces jóvenes, que deseaban ser enviados a las misiones de Indias, ya fueran orientales u occidentales, se destacan tres ejes principales de investigación. Permiten estudiar la administración europea de la vocación misionera en el seno de la orden ignaciana, sin que dispongamos aún de una visión global. A través de estos documentos personales y estereotipados se vislumbra la interiorización de la espiritualidad ignaciana, así como el grado de conocimiento de las realidades americanas y asiáticas en los colegios europeos. Combinadas con otras fuentes, son también un interesante medio para aproximarse a la relación entre la sociedad europea y las misiones de ultramar.

(Indipetae, vocación, misión, jesuitas, historiografía)

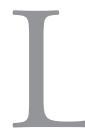

as cartas indipetae forman un conjunto de 14,067 documentos conservados en la sección Fondo Gesuitico (FG) del archivo romano de la Compañía de Jesús, Archivum Romanum Societatis Iesu (ARSI), cuyas otras dos secciones son los archivos de la "antigua Compañía" (1540-1773) y los archivos de la "nueva Compañía” (desde 1773 en adelante). ${ }^{1}$ Escritas al general de la Compa-

*aliocha.maldavsky@u-paris10.fr Agradezco Pierre-Antoine Fabre y Antonella Romano por su lectura de este texto y sus valiosas sugerencias.

${ }^{1}$ Una presentación general del archivo en Burrus 1959, Lamalle 1981-1982 y Mc Coog 2001. Los documentos misioneros del Fondo Gesuitico han sido presentados por Lamalle 1968 y Batllori 1960, 83-89. Según el padre Lamalle, las 14,067 cartas del Fondo Gesuitico fueron escritas por 6,167 redactores (Lamalle 1968, 161). También se con- 
ñía de Jesús por los jesuitas de Europa que deseaban ser enviados a las misiones de Indias, ya fueran orientales u occidentales, las cartas indipetae no parecen tener equivalente en la historia de las misiones $y$ de las instituciones religiosas. ${ }^{2}$ Era una carta personal, en el marco de la relación filial que unía cada miembro de la orden al general basado en Roma. En ella el jesuita relataba su deseo de partir a las Indias, expresando su motivación y su indiferencia hacia el destino del viaje si era elegido. La carta indipeta era para el redactor un relato espiritual de su vocación por la misión y una manifestación abierta de su motivación, un documento a la vez "espiritual y administrativo". ${ }^{3}$ Para la institución, era una prueba jurídica de la voluntad propia del candidato frente a eventuales reclamos de la familia y un instrumento de administración de las vocaciones.

Estudiadas por los historiadores jesuitas por su valor biográfico, ${ }^{4}$ las cartas indipetae como conjunto de documentos se prestan para una historia global, más allá de la historia de las misiones de evangelización, de los jesuitas, de un continente o de un país en particular. Son una excelente puerta de entrada para el estudio de la circulación de los saberes, de la espiritualidad, de la información en el mundo de la Reforma católica. Nos acercan también a la historia de la admi-

servan algunas cartas indipetae en las diferentes secciones provinciales del ARSI. Las cartas de los jesuitas alemanes de Rhenania Superior e Inferior, escritas entre 1616 y 1740, se encuentran en el Fondo Gesuitico y también en los fondos de las diferentes provincias alemanas. Véanse al respecto, Nebgen 2005, 2007.

${ }^{2}$ Según Pedro Borges, existía una correspondencia del mismo tipo en la Orden franciscana, que se conservó en la Comisaría general de Indias en Madrid, cuyos archivos desaparecieron. Borges Morán 1977, 218-219 y 1966. Adriano Prosperi cita algunas cartas enviadas a la congregación de Propaganda Fide por candidatos a las misiones en el siglo XVII, conservadas en el fondo Scritture originali riferite nelle Congregazioni Generali (s. O. C. G.), Prosperi 1996, 596-597. Se trata de pocas cartas, enviadas por sacerdotes seculares o por miembros de diversas Ordenes religiosas (Vantard 2010, 38-39). Existen también proyectos misioneros en el mismo archivo, citados por Deslandres 2003, 47-48. Los dominicos también conservan algunas cartas individuales de postulantes a las misiones así como respuestas del general de la Orden, visibles hoy en el Archivo General de la Orden de Predicadores, en el convento romano de Santa Sabina (Vantard 2010, 33).

${ }^{3}$ Son las dos palabras que utiliza Giovanni Pizzorusso para caracterizar este material de archivo. Pizzorusso 1997, 2011, 193.

${ }^{4}$ Véase al respecto la edición de seis cartas de jesuitas franceses por el padre Georges Bottereau, 1956. 
nistración y de la apropiación de las normas de comportamiento en las instituciones religiosas entre los siglos XVI y XVIII. Éstas son algunas de las pistas de investigación desarrolladas a raíz de estos valiosos documentos por los historiadores, cuyos trabajos, citados en la bibliografía, presento en los tres apartados de esta síntesis, resumiendo los resultados así como las perspectivas aún abiertas. ${ }^{5}$

En un primer punto se presenta la fuente a través de su historia como documento archivado y su dimensión material, discutiendo el lugar de estas cartas en la administración jesuita de las vocaciones misioneras. En un segundo punto se analiza el valor de estas fuentes para una historia de la circulación de la experiencia misionera y de la información en general en Europa. El tercer punto sintetiza los trabajos acerca da la espiritualidad jesuita y de su relación con la misión.

\section{ADMINISTRAR LAS VOCACIONES: PISANDO LOS UMBRALES DE LA MISIÓN}

La historia de las cartas indipetae como documentos de archivo se confunde con la política que desarrolló la Compañía de Jesús para incentivar las vocaciones misioneras en los colegios de Europa. Según Mario Scaduto, antes de 1583 las peticiones de ir a Indias fueron motivadas por la administración romana de la Orden, que hizo llamados a la misión desde 1558 y desarrolló una política de traducción de las cartas de misioneros desde la India. La correspondencia desde Roma demuestra que existe ya en los años 1560 una burocracia de la elección de misioneros, a través de registros de candidatos. ${ }^{6}$

La obligación de dar a conocer la vocación por las Indias a través de una carta indipeta sería una decisión tomada progresivamente durante los generalatos de Diego Laínez y Francisco de Borja, pro-

\footnotetext{
${ }^{5}$ Indicamos en la bibliografía los estudios consultados. Una reciente síntesis historiográfica, también en Pizzorusso 2011, 191-194.

${ }^{6}$ Scaduto $1964,376-384$. Este esfuerzo burocrático lo confirma la existencia de una encuesta pedida por Jerónimo Nadal, compañero de Ignacio de Loyola, para conocer la población jesuita de las provincias de Portugal, Castilla, Andalucía y Aragón, que visitó en 1561 y 1562 . Se trata de un cuestionario de 30 preguntas a las que respondieron 695 jesuitas, cuyas respuestas están conservadas en Fondo Gesuitico de los archivos romanos de los jesuitas (FG 77.1-77.4). Cohen 1974.
} 
bablemente para proteger la Compañía de Jesús de quejas por parte de las familias de los jesuitas elegidos. ${ }^{7}$ Su materialización en archivo empieza durante el generalato de Claudio Aquaviva, en 1583, año de las primeras cartas de la península ibérica conservadas en el Fondo Gesuitico, y su gestión administrativa se percibe concretamente a través de la conservación de listas de postulantes, cuyo nombre fue clasificado por provincia de origen y por fecha de la petición, con detalles que resumen la carta y datos de los catálogos provinciales. ${ }^{8}$ Las cartas se presentan en general en un folio, escrito en el recto y doblado, con la mención del destinatario en el verso. Su gestión material se percibe también en la anotaciones que llevan los documentos, pues se indica por ejemplo el destino que pide el candidato ("pide Indias", "pide Japon”), si se trata de una segunda carta o el destino administrativo del documento, con menciones como "messo al libro", "salutato". ${ }^{9}$ Estas cartas de los años 1580 responden a una petición por parte de Claudio Aquaviva enviada a los provinciales a más tardar en 1583 para que los jesuitas manifiesten sus deseos eventuales de ir a las Indias. ${ }^{10}$ Encontramos también estos llamados en los siglos XVII y XVIII. En 1664, Giovanni Paolo Oliva transmitió a los superiores de las provincias francesas una carta para incentivar vocaciones misioneras hacia las Antillas. ${ }^{11}$ Las cartas indipetae de los colegios de Cerdeña citan llamados de Charles de Noyelles (16821686) y Tirso Gonzalez (1686-1705). ${ }^{12}$ En 1722, el general Tamburini envió una carta general destinada a ser leída públicamente en todos los colegios europeos para informar de la falta de misioneros en las provincias de ultramar e incentivar las vocaciones. Diez años

\footnotetext{
${ }^{7}$ Fabre 2007, 77, y en prensa.

${ }^{8}$ Las cartas primera cartas enviadas por jesuitas de la península italiana son de 1589. Roscioni 2001, 112.

${ }^{9}$ Roscioni 2001, 169.

${ }^{10}$ Maldavsky 2007, 48-51. Según Gian Carlo Roscioni, la reunión de las cartas en un fondo único empezó en 1589, con el fin de controlar la selección e impedir que fueran enviados a la India jesuitas que sus superiores deseaban retener en Europa. Roscioni 2001, 112. También existen huellas de esta gestión administrativa en las cartas de las provincias alemanas, Nebgen 2005, 73.

${ }^{11}$ Pizzorusso 1997, 886.

${ }^{12}$ Véanse los testimonios citados por Turtas 2009.
} 
más tarde, el general Retz escribía una carta a todos los provinciales, apuntando las informaciones que los superiores debían mandar a Roma sobre cada candidato para facilitar la selección. ${ }^{13}$

El papel de las cartas indipetae y de los superiores romanos en la organización de las expediciones de misioneros parece variable según las provincias. El estudio de la expedición de Diego de Torres Bollo al Perú en 1604 indica que el general tuvo un papel importante, siguiendo paso a paso los trámites del procurador en Italia y en las provincias españolas, donde muchos superiores eran reticentes al envío de los miembros de sus colegios. El general intervino en la gestión del paso a América de jesuitas italianos, en principio vetado por la legislación indiana, cambiando también destinos a último minuto en función de las circunstancias. ${ }^{14}$ La elección de jesuitas para la expedición de 1604 al Perú demuestra que la carta indipeta no era indispensable, pues no todos los elegidos dejaron esa huella en los archivos. Sin embargo, aparece como un instrumento administrativo esencial para la intervención de las autoridades romanas de la Orden en el envío de misioneros a las provincias hispanoamericanas en el marco del Patronato Real.

El caso de la elección de misioneros desde Portugal es particular, pues son escasas las cartas indipetae de esta asistencia que se conservan en Roma, por lo menos para el final del siglo XvI. ${ }^{15} \mathrm{Su}$ papel pudo haber sido marginal en el marco del Padroado portugués. Al ser Portugal el principal lugar de partida para las misiones de Oriente, esta ausencia se explica quizás porque la gestión no se hacía desde Roma, sino en la misma provincia portuguesa. ${ }^{16}$ Sin embargo en el siglo XVII, las cartas indipetae aparecen más frecuentemente en los archivos romanos, lo que podría demostrar una evo-

${ }^{13}$ Capoccia 2007, 101-102. Sobre Retz y la apertura de las misiones hispánicas a los jesuitas alemanes, véase Nebgen 2005.

${ }^{14}$ Maldavsky 2007. Sobre la prohibición del paso de italianos a Indias, véase Numhauser 2007.

${ }^{15}$ Castelnau L'Estoile 2007. La asistencia, formada por provincias, era una subdivisión administrativa de la Compañía de Jesús.

${ }^{16}$ Según Edmond Lamalle, Aquaviva tuvo muchas dificultades en hacer aceptar misioneros belgas para las misiones portuguesas. Lamalle 1940, 78. Sobre la difícil internacionalización de las misiones, véase Huonder 1899, 15-20. 
lución. ${ }^{17}$ Es difícil concluir sin una contabilidad precisa de estas cartas portuguesas durante toda la época moderna. El análisis por Charlotte de Castelnau L'Estoile de la correspondencia de los superiores portugueses con el general en Roma demuestra que la expresión de la vocación individual por parte de los candidatos locales era un verdadero criterio de elección, tanto en el momento de manifestar el deseo de partir, como en el de recibir la noticia del éxito de la petición. Varios casos individuales ilustran las dificultades que planteaba este proceso de elección de misioneros y la importancia que tenía para los superiores no enviar a nadie contra su voluntad ni la de su familia, al ser la extracción social de los candidatos un parámetro considerado con atención.

La elección de los misioneros que partían desde el reino de Francia a Canadá, a las islas del Caribe o al Oriente en la segunda mitad del siglo XVII y principios del siglo XvIII obedecía también a la expresión por el candidato de su voluntad y a su cumplimiento con ciertos requisitos. De las 270 cartas indipetae de las provincias jesuitas francesas que se conservan entre 1651 y 1710 , se sabe con certeza que 72 de los candidatos obtuvieron satisfacción. ${ }^{18}$ Sin embargo, más de 800 jesuitas franceses salieron a misiones lejanas en el mismo periodo. El estudio de un grupo limitado de jesuitas de la provincia de Lyón (40 individuos) que se embarcaron efectivamente entre 1653 y 1700 demuestra que la mitad por lo menos escribió una carta indipeta, ya sea porque se conservó en el archivo o porque existe una respuesta del general. La mayoría de ellos obtuvo el destino que pidió, confirmando que se tendía a tomar en cuenta la voluntad del candidato. El caso francés confirma también el papel de las autoridades provinciales ya evidenciado para Portugal. Muchas veces los candidatos habían comunicado sus deseos a su maestro de novicios, su rector o provincial, decidiendo luego enviar la carta al general. Las respuestas de este último confirman el papel de los superiores locales,

${ }^{17}$ Liam Brockey cita numerosas cartas indipetae de jesuitas portugueses escritas en el siglo XviI y no apunta un proceso de selección exclusivamente portugués, resaltando el papel de los generales en Roma. Brockey 2007, 230-231.

${ }^{18}$ Según Noël Golvers, sólo 8 jesuitas de la provincia franco-belga, de los 90 que escribieron cartas indipetae entre 1640 y 1660, fueron elegidos. Golvers 2010. 
quienes, como en España, resienten la pérdida de sus miembros y se oponen con frecuencia a su partida. Las cartas indipetae reflejan estas tensiones internas acerca del personal de las provincias. ${ }^{19}$

De los 111 italianos que zarparon hacia el Oriente entre 1590 y 1615, estudiados por Camila Russell, sólo quedan 23 cartas indipetae. Ana Rita Capoccia estudió un grupo de 973 cartas escritas por jesuitas italianos en el siglo XVIII, de los cuales 167 precisan el o los lugares dónde quisieran ser enviados. ${ }^{20}$ La comparación entre las cartas y los catálogos del personal de las provincias americanas y asiáticas demuestra que si la carta fue un instrumento para decidir del envío de misioneros, muchos de los europeos que partieron no dejaron ningún rastro, confirmando las conclusiones de Aliocha Maldavsky, a partir del estudio de la expedición de 1604, y de Amélie Vantard sobre el caso francés. En el caso de Cerdeña, tampoco se verifica que todos los 111 sardos que atravesaron el Atlántico entre los siglos XVI y xviII, y algunos el Pacífico, dejaron una carta indipeta. ${ }^{21}$

Pero el problema se puede también invertir, considerando cómo los jesuitas redactores de cartas indipetae expresaban su decepción frente al fracaso de sus expectativas, al ver que su petición no recibía respuesta positiva. Esta dimensión ha sido estudiada para el caso de diversas provincias españolas y la provincia de Cerdeña en la segunda mitad del siglo XVII por Pascale Girard, con un análisis preciso de la evolución de los argumentos de los jesuitas que redactaron varias cartas, reiterando así su petición. ${ }^{22}$ El estudio, a la vez cuantitativo y cualitativo, confirma la importancia de la relación con los superiores locales y con los procuradores de provincias misioneras,

${ }^{19}$ Vantard 2010, 303-345. La originalidad del estudio de Amélie Vantard es que da también a conocer los procesos de elección de misioneros en la orden de Santo Domingo y en las Misiones Extranjeras de París. Es de notar que los futuros misioneros dominicos estaban mucho menos sometidos a la obediencia que los jesuitas y su elección mucho menos centralizada, a pesar de los esfuerzos de la Orden por racionalizar su proceso de elección: Vantard 2010, 346-378. Para el caso italiano, véase también Roscioni 2001, 168-174 y para el caso alemán Nebgen 2005, 74-75.

${ }^{20}$ Capoccia 2007. Russell 2011. El estudio de Russell se concentra en las misiones orientales, sin tomar en cuenta que muchos redactores pudieron también ir a América.

${ }^{21}$ Turtas 2009.

${ }^{22}$ Girard 2008. 
poniendo de relieve la movilización de relaciones interpersonales dentro de la institución y el carácter conflictivo de las negociaciones. Destaca además cómo, de carta en carta, se puede medir la interiorización de la norma de la institución por los candidatos. En efecto, las quejas sobre los superiores locales tienden a disminuir o a mencionarse de manera impersonal después de la segunda carta. Lo mismo sucede con la mención de una preferencia de destino (Indias orientales u occidentales, China o Japón, por ejemplo), en principio gobernada por la indiferencia y considerada como una prueba de la disposición a obedecer. Mientras los redactores dan generalmente precisiones en su primera carta, se vuelven más precavidos en las siguientes, como si estuvieran integrando poco a poco la norma implícita de la indiferencia.

Los estudios presentados aquí con brevedad resaltan ciertas características comunes en la administración de las vocaciones misioneras por la Compañía de Jesús. El proceso de elección de misioneros para las Indias resultaba de un equilibrio entre el general, los superiores provinciales y la voluntad individual expresada oralmente o en las cartas indipetae. Si los superiores locales aparecen como indispensables, por conocer a los candidatos y las necesidades de sus provincias, el general era una pieza esencial del circuito de elección, incluso cuando no se conservan cartas indipetae, pues mantenía una correspondencia asidua con los provinciales acerca de la organización de las expediciones. También los estudios ponen de relieve, con diferentes metodologías, la dimensión conflictiva de la elección de misioneros a Indias para las provincias europeas, cuyos superiores no deseaban ser privados de sujetos cuya formación se consideraba como una inversión. A pesar de los límites de la fuente, la existencia de una verdadera burocracia de la elección en Roma queda establecida, sin embargo, su intervención directa pudo variar según las circunstancias locales, tomando más relieve cuando se trataba de negociar el quiebre del Patronato Real, como en el caso de los italianos que pasaban a América, o era marginada en el caso del Padroado portugués. Durante todo el periodo el envío de misioneros por las diferentes monarquías tuvo un significado político que parece, sin embargo, agudizarse a medida que pasa el tiempo, por 
ejemplo, la misión a China que fue más bien un asunto portugués o francés que un asunto romano.

No existe todavía una cuantificación exhaustiva a largo plazo de la relación entre las cartas indipetae, las repuestas de los generales (que permiten suponer la existencia de una carta de petición aun cuando no se ha conservado) y los individuos que efectivamente zarparon a las Indias. Ésta permitiría tener una idea de la cronología de estas cartas y de su utilidad, según los contextos geográficos y políticos, para la administración de las misiones de ultramar por Roma.

Las cartas indipetae, al relatar una experiencia personal de vocación religiosa y apostólica, son también una fuente interesante para medir la recepción de las experiencias misioneras extraeuropeas y su influencia en la eclosión de los deseos de partir.

\section{Circulación DE LA EXPERIENCIA Misionera Y VOCACIÓN POR LA MISIÓN}

Las cartas indipetae son un índice de la circulación y de la apropiación de la información acerca de las zonas de misión y de la experiencia misionera. Si es cierto que los jesuitas disponían de elementos bastante precisos sobre sus posibles destinos, útiles para definir sus preferencias geográficas, las cartas indipetae son poco prolijas al respecto y revelan una gran inconsciencia de la realidad de la misión a la que aspiraban.

Los jesuitas redactores de cartas indipetae tenían conocimientos sobre el clima, sabían que era más fácil obtener el martirio en Japón que en Perú en el siglo XVII, entendían la importancia de aprender idiomas, conocían incluso los circuitos e itinerarios así como las costumbres de los pueblos por convertir, eliminando ciertas veces los lugares donde, según ellos, la gente iba desnuda o prefiriendo aquellos donde la vida política se consideraba comparable a la europea. ${ }^{23}$ Estos índices de la información concreta y de las representaciones en

${ }^{23}$ Pizzorusso 1997, 885-886; Maldavsky 2009, 11-12, Vantard 2010, 281-295. Sobre la búsqueda del martirio como adaptación a la geopolítica de la época moderna, véase Guerra, 2000. 
Europa de los territorios de misión aparecen generalmente en las cartas indipetae cuando los postulantes citan los lugares donde quieren ser enviados.

Para los jesuitas italianos y franceses, se confirma en general un cierto tropismo oriental. Los primeros tenían acceso a los dominios españoles, pero su preferencia iba hacia el Extremo Oriente, era la China un destino frecuentemente citado. ${ }^{24}$ También aparecen por ejemplo en 1717 las islas Filipinas, como camino hacia la China, por encontrarse entonces en Italia un procurador de Filipinas. ${ }^{25} \mathrm{~A}$ pesar de expresar con frecuencia su indiferencia, los franceses podían ir a Nueva Francia y a las Antillas francesas, además de los territorios del Medio Oriente fuera de los dominios ibéricos. ${ }^{26} \mathrm{~A}$ finales del siglo Xvil, acceden también a la China, donde se funda una misión francesa independiente de los portugueses, cuyo Padroado se ha vuelto cada vez menos influyente. ${ }^{27}$ En las cartas indipetae de Cerdeña, que pertenecía al rey de España, por depender de Aragón hasta principios del siglo XvIII, los destinos solicitados eran las Indias en forma genérica, muchas veces asociadas con Japón o Filipinas, o con el Nuevo Reino de Granada. ${ }^{28}$ Si el horizonte misionero de los jesuitas españoles era gran parte de América, no disponemos aún de suficientes trabajos detallados sobre las preferencias de los jesuitas hispánicos en sus cartas indipetae. Los jesuitas alemanes pudieron acceder de forma regular a las misiones de la América hispánica a partir de 1670, lo que causó un aumento substancial de las peticiones desde dichas provincias. ${ }^{29}$

Los principales vectores de la información y del incentivo acerca de las misiones extraeuropeas eran la literatura impresa y manuscrita que circulaba entonces en Europa dando cuenta de los "descubri-

${ }^{24}$ Prosperi 1996, 595. Imbruglia 1992, 290, Russell 2011.

${ }^{25}$ Capoccia 2007, Maldavsky 2009, 2011.

${ }^{26}$ Deslandres 1997.

${ }^{27}$ Sobre las circunstancias de las misiones francesas en China, véanse, entre otras referencias, Du Shiran y Han Qi 1992, Landry-Deron 2001, Hsia 2009. Sobre los jesuitas en China, Standaert 2001 y Brockey 2007.

${ }^{28}$ La provincia de Cerdeña siguió perteneciendo a la asistencia de España, hasta 1766, aunque estuviera bajo la tutela política de los Savoya desde 1720. Turtas 2009.

${ }^{29}$ Nebgen 2005, 78-79. 
mientos" y, sobretodo, exaltando la obra de los misioneros. ${ }^{30}$ La correspondencia impresa y manuscrita de los jesuitas, sus cartas anuas (Litterae annuae), sus compilaciones históricas y sus Cartas edificantes y curiosas, las publicaciones de las Misiones Extranjeras de París (MEP) y de la Congregación para la Propaganda Fide perseguían el objetivo de reclutar misioneros y de convencer a los eventuales proveedores de fondos. ${ }^{31}$ Es también de notar la gran influencia de la literatura hagiográfica, con vidas de mártires o de misioneros célebres, como Francisco Javier, a la vez antiguo misionero y "futuro" santo que aparece en las cartas ya a finales del siglo XVI y cuya devoción a través de novenas tuvo un impacto directo en la redacción de cartas indipetae por jesuitas franceses y belgas del siglo XVII, que ulteriores investigaciones podrían sin duda extender a otros escenarios europeos. ${ }^{32}$ No es de olvidar tampoco la influencia, fuera y dentro de los colegios, de la pintura y de los grabados, con representaciones de martirios, por ejemplo, en el refectorio del noviciado romano de Sant'Andrea o los grabados del martirio de Rodolfo Aquaviva en la India, que circulaban en Cerdeña. ${ }^{33}$ Dentro de los colegios franceses para adolescentes, el teatro y la enseñanza fueron también vectores a la vez de exaltación y de información acerca de las misiones, sobretodo a partir del siglo XVII. ${ }^{34}$

En los trabajos sobre las cartas indipetae y la vocación misionera de los religiosos europeos se mencionan frecuentemente estos in-

${ }^{30}$ Prosperi 1996, 592-597, Pizzorusso 1997, 884-886, 2011; Maldavsky 2009, 10 17, Vantard 2010, 100-131, Russell, 2011.

${ }^{31}$ La circulación y la edición en Europa de cartas desde el Oriente y de la literatura sobre las misiones jesuitas está documentada en Lach 1965, I, 314-330. Un análisis global del contenido de estas publicaciones, en Lach, 1965, I, 427-467. Sobre las cartas anuas véase Friedrich 2008. Sobre la propaganda de la MEP, véase Vantard 2010, $102-$ 107. La presencia de libros sobre las Indias en el colegio de Sassari, en Cerdeña está documentada por Turtas 2004, 2009. Acerca de la promoción de la obra misionera de los jesuitas en Lyón, véase Van Damme, p. 238-241.

${ }^{32}$ Sobre los franceses, véase Vantard 2010, 116-131. Sobre los jesuitas belgas, véanse De Groof 1998, 541 y Golvers 2010. Sobre la imitación de Francisco Javier para los jesuitas portugueses, véase Brockey 2007, 227-228.

${ }^{33}$ Dichos grabados los citan jesuitas de Cerdeña de finales del siglo Xvı, como incentivo para ingresar en la Compañía de Jesús, véase Turtas 2009. Sobre Sant'Andrea y la descripción de los grabados de mártires por Louis Richeome, véase Roscioni 2001, 77 79. Prosperi 1996, 596.

${ }^{34}$ Vantard 2010, 93-99. 
centivos que reflejan un ambiente de gran fervor misionero dentro y fuera de las instituciones religiosas. En las cartas indipetae abundan las menciones de un deseo de ir a Indias anterior al ingreso en la Compañía de Jesús, confirmando que tal vocación pudo también nacer en el seno de las familias, desarrollándose luego en el ambiente religioso de la Orden. El tema del despertar de la vocación misionera en un contexto laico es un índice para entender la penetración en las sociedades europeas de la preocupación por el horizonte apostólico del catolicismo, que la Iglesia romana consideraba como universal. ${ }^{35}$ Encontramos frecuentemente estas influencias precoces en las cartas indipetae de los siglos XVII y XVIII. Gerolamo Imbruglia, cuyo estudio se basa en cartas italianas del xvi, insiste en que se trataba de una vocación fomentada exclusivamente en el marco de los colegios. Sin embargo, Gian Carlo Roscioni, en su trabajo sobre las cartas indipetae italianas, da también frecuentes ejemplos de deseos precoces ya en los años 1570 y $1580 .^{36}$

Los jesuitas que respondieron a la encuesta pedida por Jerónimo Nadal durante su visita de las provincias ibéricas, en 1561 y 1562, confirman la idea de una vocación misionera fomentada dentro de la orden ignaciana. En su análisis de la encuesta Thomas V. Cohen apunta una contradicción entre los propósitos de la Compañía de Jesús, una orden religiosa entregada a la acción y a la transformación del mundo en el marco de la Reforma católica, y las motivaciones de los jesuitas para ingresar en ella, tema de la pregunta núm. 14. Las respuestas de los 695 jesuitas españoles y portugueses interrogados apuntan sobretodo un deseo de "servir Dios", de salvar la propia alma, de huir de los peligros y pecados del mundo, mientras que la ida a las Indias aparece sólo diez veces (1.4\%) y el martirio apenas en

\footnotetext{
35 Sobre esta dimensión véanse sobre Italia Batllori 1960 y Maldavsky 2009, 2011. Acerca del papel de los laicos en el ímpetu misionero francés, véanse Deslandres 2003, Taillandier 2003 y Vantard 2010.

${ }^{36}$ Sobre los deseos de ir a Indias antes de entrar en la Compañía de Jesús en lo siglos XVII y XVIII, véanse: De Groof 1998, 541, 548-549; Guerra 2000, 133-134; Roscioni 2001, 9, 72-73; Turtas 2004, 2009; Capoccia 2007, 97; Maldavsky 2009, 18; Vantard 2010, 83-93. Sobre el nacimiento de tal deseo exclusivamente en la Compañía de Jesús, véase Imbruglia 1992, 289.
} 
tres respuestas $(0.6 \%) .{ }^{37} \mathrm{Si}$ estas cifras parecen confirmar la opinión de Imbruglia, es de notar que muy rápidamente se multiplican las expresiones de vocaciones misioneras nacidas fuera de la orden religiosa, motivando muchas veces la elección de la Orden ignaciana. Éstas coinciden también con el periodo del generalato de Francisco de Borja, durante el cual la Compañía de Jesús tuvo un crecimiento demográfico muy importante. ${ }^{38}$ Un estudio más detallado de las cartas españolas permitiría confirmar o desmentir esta evolución, que se funda más en una impresión general que en una constatación estadística.

De confirmarse, podría explicarse por los contextos editoriales y la estructura de la publicación de cartas de jesuitas sobre el Oriente que Donald F. Lach divide en dos periodos. Según él, en un primer periodo, de 1552 a 1570, se publicaron cartas escritas entre 1548 y 1561 de manera esporádica, sin verdadero orden ni estructura. Luego, entre 1570 y 1601, la publicación de noticias desde las misiones jesuitas en Oriente fue muy escasa hasta los años 1580, para luego estructurarse mejor bajo la supervisión de las autoridades romanas de la Orden con el fin de evitar relatos inexactos y lacunarios. Se publicaron Cartas anuas oficiales (Litterae annuae) a partir de 1585, historias generales de las misiones de Oriente, como las Historiarum Indicarum del padre Maffei, publicadas en 1588, biografías y cartas de Francisco Javier se publicaron también en la última década del siglo Xvi, así como relatos de las misiones al reino Moghol, a China y a Japón. ${ }^{39}$ A esto se deben también agregar la publicación en 1585 del relato del martirio de Rodolfo Aquaviva y otros cuatro jesuitas, acaecido en la península de Salsete en 1583, la circulación de noticias sobre la visita de jóvenes nobles japoneses a Europa en $1585 .{ }^{40} \mathrm{Si}$ la vocación misional tuvo quizás mayor sus-

\footnotetext{
${ }^{37}$ Cohen 1976, 249.

${ }^{38}$ Según Dalmases García 1984, entre 1565 y 1572, los jesuitas pasaron de 3,000 a más o menos 4,000 miembros.

${ }^{39}$ Lach 1965, I, 431-467. Véase también Russell 2011. Turtas 2004, 2009, documenta en su análisis de las cartas indipetae de Cerdeña la lectura asidua de cartas a partir de los años 1580, sobretodo en Cagliari, donde las noticias llegaban antes que a Sassari.

${ }^{40}$ Roscioni 2001, 82, 97.
} 
tento editorial fuera de la Orden a partir de finales del siglo XVI, es también cierto que este auge de publicaciones coincide con las fechas de las primeras cartas indipetae archivadas como tales en Roma. Sin duda se debería estudiar con mayor atención la cronología del despertar misionero fuera y dentro de los colegios europeos, en relación con la empresa editorial y las devociones relativas a América o Asia. ${ }^{41}$ Además sería importante medir el impacto de esta literatura en las cartas indipetae redactadas por jesuitas legos, los coadjutores temporales, que no necesariamente manejaban con la misma fluidez que los estudiantes la lectura de tales obras. De manera general, no es de descartar que los vectores orales y sensibles tuvieran más peso en el nacimiento de la vocación por la misión que las lecturas, como propone Camila Russell. ${ }^{42}$

Es también un hecho que en sus colegios los jesuitas podían encontrarse con antiguos misioneros y procuradores de las diferentes provincias extraeuropeas. El paso de un procurador provocaba en general la redacción de cartas indipetae, destacándose entonces destinos poco conocidos, como las Filipinas, que gozaban en Italia de menos propaganda que China o Japón. ${ }^{43}$ Se trataba entonces de verdaderas campańas de reclutamiento de misioneros, en las cuales los procuradores se empleaban en avivar los deseos de los estudiantes y convencer a los superiores de dejarlos partir. ${ }^{44}$ Citar el encuentro con un procurador permitía también justificar la reiteración de la petición, demostrar un buen conocimiento de los circuitos de la decisión y presionar al general. ${ }^{45}$ En los colegios, los encuentros,

${ }^{41}$ Con la canonización de Francisco-Javier en 1622, y también la de Rosa de Lima, en 1671, se organizaron fiestas en Europa que fueron una oportunidad de dar a conocer la obra de los jesuitas y de los dominicos en Asia y América. Estas fiestas eran espectáculos visuales pero también tenían una prolongación escrita a través de la edición de relatos y descripciones (Breuil 2011). Una descripción de estas fiestas en Evora en Brockey 2007, 207-209, y en Francia, Cassan 2009, Taillandier 2003, 508-528.

${ }^{42}$ Russell 2011.

${ }^{43}$ Capoccia 2007, 97-98.

${ }^{44}$ Maldavsky 2007. Sobre el largo viaje de Nicolás Trigault a Europa entre 1614 y 1618 y las huellas que su paso por las provincias alemanas dejó en la documentación de cartas indipetae, véase Lamalle 1940 y Nebgen 2007, 73-78. Sobre Portugal, véase Brockey 2007, 228-229.

${ }^{45}$ Girard 2008, 54-57. Russell 2011. 
lecturas e incentivos podían generar verdaderos grupos de postulantes que se alentaban entre sí, escribían cartas colectivas, creando un clima de gran efervescencia. ${ }^{46}$ Las cartas son por eso también el barómetro de un ambiente colectivo donde los mitos, rumores y expectativas relatan una historia de la recepción de la información sobre las misiones y de su transformación por los candidatos.

En efecto, las alusiones en las cartas indipetae al trabajo real de los misioneros en el terreno son generalmente poco precisas y la "conversión de los gentiles" es más bien un topos que una acción concreta, cuya metodología se fue adaptando a los diversos terrenos durante el periodo, sin que esto aparezca claramente en las representaciones de los candidatos. ${ }^{47}$ En las cartas indipetae de los jesuitas italianos encontramos varias alusiones a las ciencias matemáticas, considerando algunos que su pericia o ignorancia los hacía aptos o inaptos a la misión en China. ${ }^{48}$ La gran reputación de los jesuitas como matemáticos e introductores de la ciencia europea en China, desde Matteo Ricci (1552-1610) en adelante, se debió a publicaciones como la de Nicolás Trigault, en 1615, a las Cartas edificantes $y$ curiosas (1702-1776), a la Description de la Chine de Jean-Baptiste Du Halde, en 1735 así como a las ulteriores publicaciones de Ferdinand Verbiest. ${ }^{49}$ Es preciso, sin embargo, relativizar esta importancia de las matemáticas en el apostolado jesuita, pues sólo una minoría de misioneros accedió a puestos científicos en Pekín, mientras que la pertinencia de tal estrategia de penetración de las elites chinas era cuestionada por los mismos jesuitas en Oriente, en una suerte de "Querella de los ritos" interna. ${ }^{50}$ Si por una parte la mayo-

\footnotetext{
${ }^{46}$ Roscioni 2001, 74; Nebgen 2005; Maldavsky 2009, 26-31, Vantard 2010, 151-154.

${ }^{47}$ Acerca de esta ignorancia e imprecisión, véanse, Brockey 2007, 209; Maldavsky 2011 y Russell 2011.

${ }^{48}$ Capoccia 2007, 96; Maldavsky 2009, 10.

${ }^{49}$ Nicolas Trigault, De Christiana Expeditione apud China, Augsbourg, Mangium, 1615. Sobre los diversos objetivos del viaje de Trigault, véase Lamalle 1940. La influencia de la publicación por Trigault de la obra de Matteo Ricci se evidencia en toda Europa, como lo demuestran las cartas indipetae alemanas estudiadas por Nebgen 2005, 2007. Sobre Du Halde y Ferbiest, véanse Landry-Deron 2002 y Golvers 2003.

${ }^{50}$ Véase al respecto la investigación de Antonella Romano sobre la querella acerca de la presencia de jesuitas en el Tribunal de las matemáticas de Pekín, denunciada en 1649 como un incentivo a la idolatría. Romano 2004. Esta querella revela la tensión entre el
} 
ría de los jesuitas en China se ocupaba en misiones rurales, no es tampoco evidente que los candidatos a la misión china fueran elegidos en Europa en función de su pericia científica, pues los jesuitas que residieron en China no necesariamente fueron como matemáticos. ${ }^{51}$ Por lo tanto, la conexión que podemos encontrar en las cartas indipetae entre las matemáticas y la misión a China resulta de un conocimiento parcial, fruto de la propaganda y de la construcción de una reputación que los jesuitas mismos querían valorar acerca su acción en Asia oriental. ${ }^{52}$ Esta propaganda que conectaba la China con las matemáticas encontró sin duda un público interesado en el prestigio social e intelectual que suponía participar en tal empresa y que iba más allá de la misma Compañía de Jesús, como lo demuestra el ejemplo de los jesuitas milaneses. ${ }^{53}$

Refiriéndose al conocimiento de los indígenas americanos, y particularmente de la Nueva España, De Groof escribe: "Los novicios flamencos realmente no sabían mucho acerca de los indígenas, salvo que supuestamente eran peligrosos" ${ }^{54}$ Los efectos de esta discordancia los encontramos en la misma correspondencia misionera y en fuentes complementarias que revelan los equívocos sobre las misiones en la mente de los postulantes europeos, resaltando su falta de preparación a la realidad extraeuropea. Ya en los años 1570, algunos superiores de los colegios orientales recomendaban al general en Roma mucha cautela en la selección de los misioneros, para evitar hombres de poco celo o inadaptados, al ser Alessandro Valignano, quien actuó como superior en las provincias de Oriente entre 1575 y

apostolado y la ciencia, así como la paulatina autonomización de la figura del científico en la Compañía de Jesús. Véase también al respecto, Romano 2011.

${ }^{51}$ Sobre la formación científica de los jesuitas de las misiones orientales, en Portugal y en Macao, véanse Leitão 2003, Leitão y Saraiva 2002 y Baldini 2008. Sobre la realidad concreta de las misiones jesuitas en China, véanse Standaert 2001, Brockey 2007, 209-210.

${ }^{52}$ Este aspecto está documentado por Noël Golvers acerca de la obra de Ferdinand Verbiest (1623-1688), misionero en China y, de forma más general, por Liam Brockey. Golvers 2003, 53-58; Brockey 2007, 209, 215-217.

${ }^{53}$ La publicación en Milán de la correspondencia de Giacomo Rho, jesuita milanés que acompańó Adam Schall a la China con su familia es una ilustración de esta conexión entre la misión y el prestigio social. Maldavsky 2011.

${ }^{54}$ De Groof 1998, 548. 
1587, el principal consejero de Everardo Mercurian y Claudio Aquaviva al respecto..$^{55}$ Las quejas que algunos jesuitas del Perú formulaban en la primera mitad del siglo XVII acerca de los religiosos europeos que les eran enviados son reveladoras al respecto, así como los lamentos de Jacques de Bourges, misionero en Asia y redactor en 1668 de una carta sobre las cualidades de los misioneros, conservada en los archivos de las MEP. ${ }^{56}$ La representación que tenían los religiosos europeos dependía de una producción literaria que resaltaba las grandes realizaciones de los misioneros, los mártires católicos y la infinidad de almas por convertir. ${ }^{57}$ Para De Groof, "la estrategia jesuita buscaba de manera explícita colmar a los jóvenes novicios de admiración hacia los mártires y de la ardiente aspiración a imitarlos". ${ }^{58}$ Los mismos procuradores de las provincias jesuitas de América sabían que tenían mayores posibilidades de seducir a los religiosos europeos describiendo las misiones fronterizas con los indios considerados como bárbaros del Paraguay, donde iban en realidad pocos misioneros, en vez de los colegios peruanos donde residía la mayoría de los jesuitas que se embarcaban, empleándose con españoles. ${ }^{59}$

Las cartas demuestran que la experiencia de la misión lejana no era un saber que circulaba entre las provincias misioneras y Europa y que se podía acumular, tratándose el proyecto misionero individual de una permanente "primera vez". Estas diferencias entre la imagen de las misiones que revelan las cartas indipetae, la realidad concreta y la propaganda merecerían ser investigadas con mayor profundidad, ampliando el espectro geográfico. No es de descartar la idea que la Compañía de Jesús mantuviera deliberadamente una imagen imprecisa y hasta errónea de sus provincias extraeuropeas, con el fin de fomentar la vocación misionera a través de tópicos ca-

${ }^{55}$ Roscioni 2001, 98-102 y 112.

${ }^{56}$ Roscioni 2001, 102-104, Maldavsky 2006, Acosta 2007, Numhauser 2007, Maldavsky 2011, 47-51, en prensa: 2012. Sobre Jacques de Bourges, Vantard, 2010, $397-$ 404. Véanse también, sobre Asia en el siglo XIx, las cartas publicadas por Catherine Marin, 2007.

${ }^{57}$ Prosperi 1991, 183; 1996, 592-595; Pizzorusso, 1997, 892-893; Roscioni 2001, 68-72; Maldavsky 2009, 12-13; Vantard 2010, 100-116.

${ }^{58}$ De Groof 1998, 544.

${ }^{59}$ Maldavsky 2007, 2009, 2011. 
paces de estimularla porque correspondían a las aspiraciones espirituales, y también mundanas, de los candidatos. En ese sentido, estas fuentes son un instrumento de gran valor para medir las transformaciones de la idea de misión en la Europa moderna.

ESPIRITUALIDAD, JUVENTUD Y TRANSFORMACIÓN DE LA IDEA DE LA MISIÓN

A pesar del cambio que se percibe en la idea de la misión durante el siglo XVI, los candidatos siguen exponiendo una concepción individual y medieval del apostolado, donde domina por ejemplo el modelo del martirio, dando la impresión que ignoraban la experiencia misionera concreta de sus compañeros. Esta importancia del martirio como motivación por las Indias se mezcla con una serie de motivos cuya dimensión apostólica no es del todo evidente, demostrando que la coincidencia entre la vocación misionera y la vocación de las Indias es un problema histórico.

Una de las temáticas importantes del tratamiento historiográfico de las cartas indipetae ha sido su dimensión espiritual. Ésta fue resaltada por los mismos historiadores de la Compañía de Jesús, al ser estas cartas un "índice" de la espiritualidad misionera en la Orden y una ilustración de los Ejercicios espirituales de Ignacio de Loyola. ${ }^{60}$

El martirio como motor de la vocación misionera aparece constantemente en las cartas indipetae, como ya lo hemos subrayado. ${ }^{61}$ Más que una sed de aventuras se trata sobretodo de la expresión de una espiritualidad que resultaba de la identificación con Cristo, presente en los Ejercicios espirituales de Ignacio de Loyola, e íntimamente relacionada con la noción de indiferencia o sea de disponibilidad y obediencia a la voluntad de Dios. La correlación entre las cartas indipetae, el vocabulario de la elección y la experiencia de los Ejercicios espirituales en la Compañía de Jesús ha sido subrayada por varios historiadores con diferentes perspectivas.

${ }^{60}$ De Guibert 1953, Bottereau 1956, Batllori 1960.

${ }^{61}$ Morineau 1987, Imbruglia 1992, 294; Guerra 2000, 135-136; Roscioni 2001, 81-96; Turtas 2009. 
Charlotte de Castelnau estudió para Portugal el vocabulario del discernimiento inspirado por Ignacio de Loyola en sus Ejercicios espirituales, poniendo de relieve la importancia de la vocación y de la elección en el sistema espiritual jesuita a través de términos como "consuelo", "voluntad", "contento". Al ser la misión una elección definitiva, tal como el matrimonio o el ingreso en una orden religiosa, el método ignaciano de discernimiento era importante a la vez para el postulante y para los superiores, que debían estar seguros de su elección. En ese sentido la dimensión espiritual de la carta estaba íntimamente relacionada con su empleo administrativo. ${ }^{62}$

La oración contemplativa que proponen los Ejercicios permite que surjan deseos latentes, ayuda a ordenarlos y a alcanzar la indiferencia y la consolación, condiciones para renunciar a sí mismo y adaptarse al mundo, donde los jesuitas actúan para la salvación de los otros y de sí. De ahí el lazo entre los Ejercicios espirituales y el apostolado como peregrinación. Existe, según Gerolamo Imbruglia, una relación estrecha entre la actividad apostólica y la "meditación sobre la muerte" que aparece en los Ejercicios espirituales. ${ }^{63}$ Este lazo lo apunta también Pierre-Antoine Fabre, en su análisis de un grupo de cartas indipetae escritas por jesuitas que obtuvieron la autorización de ir a Filipinas a finales del siglo xvi. Retrato de sí mismo ofrecido al general, la carta indipeta es también una meditación, una quinta semana de los Ejercicios espirituales de Ignacio de Loyola y una prolongación del proceso de conversión espiritual a través de la vocación por las Indias. Insta Fabre a investigar acerca de las diferentes versiones de los Ejercicios espirituales que circularon en Italia y España en los años 1560 y sobre el valor de la "meditación sobre la muerte" que Jerónimo Nadal agregó a la copia que llevó a España. ${ }^{64}$

Los trabajos de historia de la psicología de Marina Massimi y de sus colaboradores se han concentrado exclusivamente en un análisis de la carta indipeta como expresión de una subjetividad y a la vez del saber psicológico desplegado por los jesuitas a través de las nociones

${ }^{62}$ Castelnau L'Estoile 2007.

${ }^{63}$ Imbruglia 1992, 296-297, 299-301 y 305. Sobre las cartas indipetae y los Ejercicios espirituales, Vantard 2010, 216-222.

${ }^{64}$ Fabre 2007, 79. 
de discernimiento, de conocimiento de sí, de obediencia, de indiferencia, de consolación. Esta serie de estudios se detiene atentamente en la filiación de las cartas indipetae con los escritos espirituales de Ignacio de Loyola, y más allá con las raíces aristotélico-tomistas de la norma retórica y teológica que despliegan estos documentos. Disciplinar los propios deseos era el camino para sentirse indiferente y libre, lograr un equilibrio entre el entendimiento, la voluntad y los afectos y acceder al "bien último", la voluntad divina, según la lectura que Santo Tomás hacía de Aristóteles. Al lograr la indiferencia, el jesuita accedía a la consolación como "experiencia de libertad", elegía su destino de manera ordenada, disciplinando sus pasiones con la razón y haciendo coincidir su voluntad con la vocación divina. ${ }^{65}$ A través de su repetición y a pesar de los estereotipos que parecen vehicular, las cartas indipetae eran la expresión de una norma que no contradecía "la expresión del individuo y de su vivencia personal" . ${ }^{66}$

El modelo espiritual de la misión y del apostolado, como "dimensión fundamental de la vocación sacerdotal", no se limitó a los jesuitas. Durante el siglo XVII se manifestó claramente en Francia, al ser la figura de Francisco Javier un verdadero modelo para todos los actores de la Reforma católica, dentro y fuera de la Compañía de Jesús. Los misioneros y los mártires personificaban la imitación de Jesús y de los apóstoles, por su disponibilidad e indiferencia hacia los lugares de misión, signos de humildad y de obediencia a los superiores. Para los jesuitas, la "indiferencia" era una actitud espiritual que la misión, como peregrinatio, realizaba plenamente. Los misioneros, y sobretodo los mártires, ofrecían además "el modelo de una vida de sufrimiento por Cristo" que podía culminar con la muerte, pero que concretamente significaba la renuncia a sí mismo.$^{67} \mathrm{La}$ necesaria indiferencia por el destino geográfico, considerada por la Compañía de Jesús como una prueba de la disponibilidad y obediencia del candi-

\footnotetext{
${ }^{65}$ Massimi 1999; Souza y Massimi 2002; Massimi y Prudente 2002; Leal de Barros y Massimi 2005; Pacheco y Massimi 2005, 2010.

${ }^{66}$ Pacheco 2004, 50. En su análisis microhistórico, Paulo Roberto de A. Pacheco estudia 23 cartas escritas por 23 jesuitas españoles, entre 1583 y 1609, cuya transcripción reproduce en los anexos de la tesis.

${ }^{67}$ Dompnier 2002; Vantard 2010.
} 
dato e interiorizada por él, explica sin duda el carácter impreciso de la evocación de los lugares de misión por los redactores.

Estos modelos de espiritualidad, particularmente fértiles para provocar el "deseo de las Indias", tenían una estrecha relación con una concepción medieval de la misión que no se correspondía, según Giovanni Pizzorusso, con su evolución real en el siglo xvir. ${ }^{68} \mathrm{La}$ hazaña individual del misionero, que seguía siendo un modelo para la espiritualidad de la época, contrastaba con una concepción del apostolado en la que prevalía más bien la continuidad de la evangelización y su dimensión institucional. ${ }^{69}$ Por eso no es de extrañar que mientras que en la Compañía de Jesús se pudo criticar la búsqueda del martirio por Antonio Criminale en la India, así como las tendencias milenaristas inspiradas por el ejemplo de Francisco Javier, se seguía fomentando la imitación de estos misioneros en la propaganda religiosa para promover la unión y la fuerza de los jesuitas, cuyo resultado encontramos en las cartas indipetae. ${ }^{70}$ Esto se explica sin duda porque el deseo de martirio no significaba que fuera necesario buscar el sacrificio concreto. Se trataba más bien de un ideal inalcanzable, según los franceses Jean Eudes y Vincent de Paul, representantes de la escuela de espiritualidad francesa en el siglo xvII. ${ }^{71}$ Según Camila Russell, la evocación del martirio en las cartas indipetae de los jesuitas italianos de finales del siglo XvI y principios del siglo xviI se refiere en general a modelos antiguos de principios del cristianismo y no a ejemplos recientes, contrastando con las menciones que se encuentran en las cartas de mediados de siglo, citadas por Pizzorusso, y del siglo XviII, estudiadas por Capoccia. ${ }^{72}$ Tal evolución es, según Russell, una ilustración de la interiorización por los jesuitas del siglo Xvi de la necesidad de convocar la tradición para

${ }^{68}$ Pizzorusso 1997, 887-894.

${ }^{69}$ Prosperi 1992, 1996, 595-597.

${ }^{70}$ Para documentar las críticas al martirio de Criminale, véanse Imbruglia 1992, 291, Roscioni 2001, 27-43, y la comparación por Bernard Vincent de la crítica de Juan Polanco al martirio de Criminale en la India y de Francisco de Borja sobre la muerte del padre Martínez en la Florida en 1566, Grupo, p. 324-329. Acerca del deseo de martirio como expresión del "amor mutuo" en el seno de la Compañía de Jesús, véase Guerra, p. 136-137.

${ }^{71}$ Dompnier 2002, 66-67.

${ }^{72}$ Pizzorusso 1997, Capoccia 2007, Russell 2011. 
establecer su autoridad, mientras que en el periodo siguiente los ejemplos de la Compañía de Jesús adquirieron un valor suficiente. ${ }^{73}$

Estas contradicciones y evoluciones presentes en las cartas indipetae confirman el carácter sumamente fértil de estos documentos para estudiar el camino de la interiorización de las normas espirituales ignacianas a través de Europa durante los siglos XVI y XVII. También la vocación por la misión, a través del martirio o no, tuvo una connotación social que sería esencial investigar con mayor profundidad.

Según Gian Carlo Roscioni, las cartas indipetae son fuentes únicas para acceder a la prosa de jóvenes europeos del siglo XVII sobre sí mismos, sobre sus sueńos y sus expectativas, ${ }^{74}$ aunque abunden los ejemplos de redactores de indipetae ya mayores y alejados de sus años de noviciado. ${ }^{75}$ Como lo resaltaban los mismos superiores que acogían a jóvenes inexpertos en las provincias de América o de la India, y como ya lo hemos indicado, las motivaciones de los redactores de indipetae tenían matices muy diversos donde se confundía la vocación apostólica con la búsqueda de nuevos horizontes que no tenían solamente una dimensión espiritual. Conocer nuevas tierras y nuevos pueblos, enfrentarse con peligros y sufrimientos inéditos, alejarse de su familia, de su casa, ciudad y región eran algunos de los objetivos perseguidos con la redacción de estas cartas, más allá de la motivación por la misión en sí. Eso explica que muchos, a pesar de ser conscientes de las posibilidades de apostolado abiertas en la misma Europa, o sea en las Indias del interior, excluían explícitamente las misiones europeas. ${ }^{76}$ Ya el acto de ingresar en la Compañía de Jesús, nueva familia del jesuita, significaba cambiar de vida y de ambiente, poner distancia entre sí y los suyos. Sin embargo, muchas son las cartas que indican que esta distancia no era suficiente y que la familia seguía siendo un peso para muchos de ellos en Europa, explicando

${ }^{73}$ Russell 2011.

${ }^{74}$ Roscioni 2001, 115.

${ }^{75} \mathrm{La}$ edad de los redactores no ha sido estudiada de manera sistemática. De las 66 cartas de jesuitas de la provincia de Lyón estudiadas por Amélie Vantard en los periodos 1653-1660 y 1691-1698, 25 redactores tenían menos de 30 años y solo 9 habían pasado menos de cinco ańos en la Compañía de Jesús. Vantard 2010, 196.

${ }^{76}$ Sobre la relación entre las Indias de ultramar y "nuestras Indias", véanse los trabajos de Prosperi 1982, 1996 y Guerra 2000, Selwyn, 95-137. 
así su motivación por las misiones lejanas. La relación entre la misión y la familia invita a plantear la cuestión de la vocación misionera en términos sociales, más allá de la idea recurrente de que para las familias pudo ser un desgarro la partida de uno de sus miembros a China o a América. El topos de la familia como obstáculo a la entrada en las órdenes religiosas o al viaje misionero se verifica frecuentemente, cuando por ejemplo los religiosos eran hijos varones únicos y tenían hermanas por casar, y era recomendado por la institución desarrollar un "santo odio" hacia la familia para poder realizar su vocación. ${ }^{77} \mathrm{Sin}$ embargo, es preciso plantear también el problema desde el punto de vista de los mismos candidatos a la misión, cuya extracción social merecería una atención particular. Si nos transportamos a los colegios de donde partían las cartas indipetae y pensamos en el ambiente de emulación que pudo existir en ellos, es preciso tener en cuenta nociones como el honor o el desafío. Desvelar su deseo de ir a Indias y luego desdecirse era un motivo de escándalo en el microcosmo de un colegio jesuita, porque dar el paso de escribir la carta indipeta era considerado como una forma de coraje y de valentía. ${ }^{78}$ En ese sentido se puede también interpretar la noción de martirio, que algunos jesuitas consideraban como una manera de evitar morir en su cama, como una muerte honrada, comparable al destino de los soldados con cuyo ejemplo muchos de los jesuitas convivieron en sus propias familias. ${ }^{79}$ Esto no significa que los jesuitas que pedían ir a las misiones no tuvieran celo apostólico, pero éste se mezclaba sin duda con sus motivaciones sociales. Y es de considerar la misión extraeuropea como un horizonte comparable a cualquier carrera de soldado, fuente de honor y de consideración en una sociedad que seguía valorando el compromiso militar a pesar de las mutaciones de sus elites nobiliarias. ${ }^{80}$ El mito de la Cruzada, cuya diferencia con la misión apunta

\footnotetext{
77 Sobre la familia y las misiones, véanse Prosperi 1996, 596-597; Guerra 2000, 145 146; Roscioni 2001, 149-161 (capítulo intitulado "Il santo odio"); Castelnau L'Estoile 2007; Vantard 2010, 382-397. Un ejemplo de familia favorable a la vocación misionera en Maldavsky 2009, 2011.

${ }^{78}$ Dos ejemplos en Castelnau L'Estoile 2007 y Maldavsky 2009.

${ }^{79}$ Véase el testimonio citado por Roscioni 2001, 137, o el ejemplo de los Cignardi, destacado por Maldavsky 2009, 2011.

${ }^{80}$ Este hecho se confirma en el caso de la nobleza italiana, cuyo compromiso militar
} 
Gian Carlo Roscioni, formaba, sin embargo, parte de la religiosidad y de la cultura de los jóvenes europeos del siglo XVII, entre Lepanto y la paz de Passarowitz. ${ }^{81} \mathrm{Al}$ ser la metáfora guerrera un leitmotiv en el vocabulario de la Reforma católica y de la misma Compañía de Jesús, su uso en las cartas indipetae revela una interiorización de los tópicos de la época, cuya variación geográfica y generacional sería útil investigar con mayor atención desde el punto de vista de una historia social de la misión.

La administración interna del envío de misioneros a las Indias aparece bastante bien documentada por la historiografía de las cartas indipetae, por ser un campo de investigación cuyas fuentes se limitan a los archivos de la misma orden religiosa. Falta sin embargo una visión global en cifras que dichas fuentes permitirían hacer a pesar de las lagunas documentales. También se ha aprendido mucho sobre la interiorización de la espiritualidad ignaciana por los jesuitas y la filiación entre las cartas indipetae, los escritos de Ignacio de Loyola y la filosofía del Renacimiento, a pesar de que la genealogía precisa de la recepción de los Ejercicios espirituales en Europa se podría profundizar mucho más.

La relación entre el contenido mismo de las cartas, su evolución cronológica y geográfica y la empresa editorial europea de propaganda por las misiones está sin duda aún por dibujar de manera más precisa, sobretodo en el universo hispánico, cuya producción de cartas indipetae no ha sido suficientemente estudiada.

De manera general, las cartas indipetae, cuando se combinan con otras fuentes, son una excelente puerta de entrada para una historia social y cultural del ímpetu misionero en Europa en la época moderna que va más allá de la Compañía de Jesús y abarca las sociedades de la Reforma católica en su conjunto.

siguió vigente durante el periodo de dominación de los Austrias en Lombardía, como lo demuestra Claudio Donati 2007. Una reflexión sobre el compromiso religioso y militar de la nobleza europea en Boltanski y Mercier 2011.

${ }^{81}$ Roscioni 2001, 137-139. Acerca del mito de la cruzada en la época moderna, véanse Dupront 1995, Alphandéry y Dupront 1997, y su discusión por Géraud Poumarède 2004, 534. Acerca del eco del conflicto contra los otomanos en Italia en el siglo XVII y su percepción por los jesuitas, véanse Ricci 2002 y 2009 y Colombo 2009. 
CUADRO de las cartas Indipetae conservadas en el archivo romano de la Compañía de Jesús: Archivo de la Antigua Compañía y FG532 a FG751

\begin{tabular}{llll}
\hline Fondo & Signatura & Proveniencia & Fechas \\
\hline Fondo Gesuitico & FG 732 & Italia & Sin fechas \\
Fondo Gesuitico & FG 733 & Italia & $1589-1606$ \\
Fondo Gesuitico & FG 734 & Italia & $1607-1615$ \\
Fondo Gesuitico & FG 735 & Italia & $1616-1618$ \\
Fondo Gesuitico & FG 736 & Italia & $1619-1622$ \\
Fondo Gesuitico & FG 737 & Italia & $1623-1624$ \\
Fondo Gesuitico & FG 738 & Italia & $1627-1629$ \\
Fondo Gesuitico & FG 739 & Italia & $1630-1633$ \\
Fondo Gesuitico & FG 740 & Italia & $1634-1636$ \\
Fondo Gesuitico & FG 741 & Italia & $1637-1638$ \\
Fondo Gesuitico & FG 742 & Italia & $1639-1640$ \\
Fondo Gesuitico & FG 743 & Italia & $1641-1642$ \\
Fondo Gesuitico & FG 744 & Italia & $1643-1646$ \\
Fondo Gesuitico & FG 745 & Italia & $1647-1649$ \\
Fondo Gesuitico & FG 746 & Italia & $1650-1655$ \\
Fondo Gesuitico & FG 747 & Italia & $1656-1671$ \\
Fondo Gesuitico & FG 748 & Italia & $1672-1684$ \\
Fondo Gesuitico & FG 749 & Italia & $1685-1695$ \\
Fondo Gesuitico & FG 750 & Italia & $1696-1717$ \\
Fondo Gesuitico & FG 751 & Italia & $1718-1770$ \\
Fondo Gesuitico & FG 752 & Flandro-Bélgica & $1607-1726$ \\
Fesuitico & FG 753 & Flandro-Bélgica & $1661-1730$ \\
& FG 754 & Germania Sup. & $1661-1770$
\end{tabular}


CUADRO de las cartas Indipetae conservadas en el archivo romano de la Compañía de Jesús: Archivo de la Antigua Compañía y FG532 a FG751 (continuación)

\begin{tabular}{llll}
\hline Fondo & Signatura & Proveniencia & Fechas \\
\hline Fondo Gesuitico & FG 755 & Austria & $1614-1730$ \\
Fondo Gesuitico & FG 756 & Bohemia & $1624-1678$ \\
Fondo Gesuitico & FG 757 I & Gallia & $1633-1761$ \\
Fondo Gesuitico & FG 757 II & Lusitania & $1627-1717$ \\
Fondo Gesuitico & FG 758 & Hispania & $1583-1604$ \\
Fondo Gesuitico & FG 759 & Hispania & $1605-1726$ \\
ARSI & Gall. Belg. 45 & Francia Bélgica & $1615-1682$ \\
ARSI & Ital. 173 & Italia & $1580-1765$ \\
ARSI & Ven 99 & Italia & $1638-1754$ \\
ARSI & Hisp 88 y Hisp 88a & España & $1584-1704$ \\
ARSI & Germ. Sup 18 I-II-III & Germania Superior & $1612-1729$ \\
ARSI & Rhen. Sup. 42 & Rhenania Superior & $1616-1728$ \\
ARSI & Rhen. Inf. 15 & Rhenania Inferior & $1616-1740$ \\
ARSI & Pol. 79 & Polonia Lituania & $1687-1723$ \\
\hline
\end{tabular}

Precisiones:

* Fondo Gesuitico, FG732 a FG759 (28 legajos). Existe un índice alfabético general de la colección, así como índices parciales.

* Otros fondos del ARSI que contienen cartas italianas y españolas:

Algunas cartas indipetae italianas se conservan en el fondo italiano del ARSI: ARSI, Ital. 173, "Missiones et servitium peste infectorum petentes". Contiene una carta indipeta del siglo xvI ( $c$ a. 1580), un centenar del siglo XVII (f. 2-101) y unas pocas del siglo XVIII (f. 102-108). Contiene además listas de redactores de Indipetae de las provincias de Roma, Milán y Venecia (años 15801590).

* El volumen FG759, donde se encuentran las cartas indipetae de jesuitas espańoles, escritas entre 1605 y 1730, contiene además listas de redactores de cartas indipetae, de las provincias de Aragon 1583-1604 (f. 680-681) y Sardeña 1583-1603 (f. 682-683). El volumen Hisp.88a, "Indiam Petentes 1584-1704" conserva para el siglo xvi: listas de redactores de cartas indipetae de las provincias de Castilla y Aragón clasificadas por año entre 1584 y 1604. Contiene 103 cartas redactadas entre 1673 y 1704 . El volumen Hisp.88, "Indiam Petentes 1623-1705", contiene las cartas de esas fechas además del índice del volumen Hisp.88a. 


\section{BibliografíA}

Acosta, Antonio, “¿Problemas en la expansión misionera jesuita a comienzos del siglo xvir? Gerónimo Pallas en el Perú y su 'Misión a las Indias?"”, en Laura Laurencich Minelli y Paulina Numhauser, eds., Sublevando el Virreinato. Documentos contestatarios a la historiografía tradicional del Perú colonial, Quito, AbyaYala, 2007, 37-72.

Alphandéry, Paul, Alphonse Dupront, Michel Balard, La chrétienté et l'idée de croisade, París, Albin Michel, [1954-1959] 1995.

BALDINI, Ugo, "The Jesuit college in Macao as a meeting point of the European, Chinese and Japanese Mathematical Traditions. Some remarks on the present state of research, mainly concerning sources (16th-17th centuries)", en Luis Saraiva y Catherine Jami, eds., History of Mathematical Sciences: Portugal end the East, III. The Jesuits, the Padroado and East Asian Science (15521773), Singapore, World Scientific, 2008, 33-79.

BATLlori, Miquel, "Note sull'ambiente missionario nell'Italia del Cinquecento", en Hubert Jedin, Problemi di vita religiosa in Italia nel Cinquecento, Padova, Antenore, 1960, 83-89.

Borges Morán, Pedro, El envio de misioneros a América durante la época española, Salamanca, 1977.

Borges, Pedro, "Notas sobre el desaparecido archivo matritense de la Comisaría General de Indias", Archivo Ibero Americano, 26, 1966, 150-152.

Bottereau, Georges, s.J., "Quitter l'Europe et ses délices", Christus, Edición de seis cartas de jesuitas franceses, 1956, 529-545.

BreuIL, Mélanie, Un regard sur les Indes au XVIIe siècle. Les hagiographies et les relations de fêtes, Mémoire de Master 2, Université Paris Ouest Nanterre La Défense, 2011.

Brockey, Liam Matthew, Journey to the East: The Jesuit Mission to China, 1579-1724, Harvard University Press, 2007.

Burrus, Ernest J., s.J., "Research Opportunities in Italian Archives and Manuscript Collections for Students of Hispanic American History", The Hispanic American Historical Review, vol. 39, núm. 3, agosto 1959, 428-463. 
Capoccia, Ana Rita, “Un’ipotesi di lettura delle Indipetae italiane del Settecento: desiderio di martirio e 'indifferenza", en Bernard Vincent y Pierre-Antoine Fabre, ed., Notre lieu est le monde. Missions religieuses dans le monde ibérique à l'époque moderne, Roma, Ecole française de Rome, 2007, 89-110.

Castelnau-L'Estoile, Charlotte de, "Élection et vocation: Le choix des missionnaires dans la province jésuite du Portugal (1592-1596)", en Bernard Vincent y Pierre-Antoine Fabre, ed., Notre lieu est le monde. Missions religieuses dans le monde ibérique à l'époque moderne, Roma, Ecole française de Rome, 2007, 21-43.

Cassan, Michel, "Les fêtes de la canonisation d'Ignace de Loyola et de François Xavier dans la province d'Aquitaine (1622)”, en Bernard Dompnier, Les cérémonies extraordinaires du catholicisme baroque, Clermont-Ferrand, Presses Universitaires Blaise Pascal, 2009, 459-476.

Codignola, Luca y Giovanni Pizzorusso, “Les lieux, les méthodes et les sources de l'expansion missionnaire du Moyen Âge au XVIIe siècle: Rome sur la voie de la centralisation", en Laurier Turgeon, Denis Delâge y Réal Ouellet, ed., Transferts culturels et métissages Amérique/Europe, XVIe-XXe siècle, París, L'Harmattan, 1996, 489-512.

Cohen, Thomas V., "Why the Jesuits Joined. 1540-1600", Communications historiques. La société historique du Canada, 1974, 237-258.

, “Diversità nell' Esperienza Religiosa tra i primi 1259 Gesuiti", Annali Accademici Canadesi, I, 1986, 7-25.

Соцомво, Emanuele, "Jesuits and Islam in Seventeenth-Century Europe: War, Preaching and Conversions”, en Bernard Heyberger, Mercedes García-Arenal, Emanuele Colombo, Paola Vismara, L'islam visto da Occidente: cultura e religione del Seicento europeo di fronte all'islam, Genova-Milán, 2009, 315-340.

Cymbalista, Renato, "Os mártires e a cristianização do território na América portuguesa, séculos XVI e XVII", Anais do Museu Paulista, NS 18/1, 2010, 43-82.

, "The presence of the martyrs: Jesuit martyrdom and the 
Christianisation of Portuguese America", International Journal for the study of the Christian Church 10/4, 2010, 287-305.

Dalmases García, C. de, s.J., "Estado de la Compañía al final del generalato de San Francisco de Borja", Archivum Historicum Societatis Iesu, núm. 105, 1984, 55-83.

De Groof, Bart de, "Encuentros discordantes. Expectativas y experiencias de los jesuitas belgas en el México del siglo xvII", Historia Mexicana, 47-3, 1998, 537-569.

Deslandres, Dominique, "Les missions françaises intérieures et lointaines, 1600-1650", Mélanges de l'École Française de Rome. Italie Méditerranée, tomo 10, 2-1997, 505-538.

Dompnier, Bernard, "Mission lointaine et mission de l'intérieur chez les Capucins français de la première moitié du XVIIe siècle", en Les réveils missionnaires en France du Moyen Age à nos jours (Lyon, 1980), París, Beauchesne, 1984, 91-106.

"Mission lointaine et spiritualité sacerdotale au XVIIe siècle", en L'espace missionnaire: lieux d'innovation et de rencontres interculturelles (Québec, otoño 2001), Québec-París, 2002, 49-68.

Donati, Claudio, "The Profession of Arms and the Nobility in Spanish Italy: Some Considerations", en Thomas James Dandelet, John A. Marino, Spain in Italy: politics, society, and religion 1500-1700, Leiden, Brill, 2007, 299-324.

Du Shiran y Han Qi, "Contribution des jésuites français à la science chinoise aux XVIIème et XVIIIème siècles", Impact of Science on Society, 167, 1992, 275-285.

Dupront, Alphonse, Le mythe de croisade, París, Gallimard, 1997.

FABRE, Pierre-Antoine, "Un désir antérieur. Les premiers jésuites des Philippines et leurs indipetae (1580-1605)", en Bernard Vincent y Pierre-Antoine Fabre, ed., Notre lieu est le monde. Missions religieuses dans le monde ibérique à l'époque moderne, Roma, Ecole française de Rome, 2007, 71-88.

"La décision de partir comme accomplissement des Exercices: Une lecture des Indipetae", en Thomas McCoog, Ite inflammate omnia: selected historical papers from conferences held at Loyola and Rome in 2006, Roma, Istitutum Historicum Societatis Iesu, 2010, 45-70. 
,Les premiers temps de la mission américaine de la Compagnie de Jésus à l'époque du généralat de Francisco de Borja”, Madrid, en prensa.

Friedrich, Markus, "Circulating and Compiling the Litterae Annuae. Towards a History of the Jesuit System of Communication", Archivum Historicum Societatis Iesu, 77, 2008, 3-39.

Girard, Pascale, “Por motivos tan rateros'. Les effets du refus dans les Indipetae des jésuites d'Espagne et de Sardaigne au XVIIe siècle", en S. Alexandre, F. Bock y G. Bührer-Thierry, coord., L'échec en politique: objet d'histoire, París, L'Harmattan, 2008, 49-66.

Golvers, Noël, "Les Litterae Indipetae et les raisons profondes des vocations pour la Chine dans les Pays-Bas du Sud en 16401660", Courrier Verbiest, XII, diciembre 2000, 4-5, y xIII, junio 2001, 6-7.

, Ferdinand Verbiest, S.J. (1623-1688) and the Chinese heaven: the composition of the astronomical corpus, its diffusion and reception in the European republic of letters, Lovaina, Leuven University Press, 2003.

, "Litterae Indipetae from the Jesuit Provincia Flandro-Belgica 1640/1660-1700”, Roman Malek y Gianni. Criveller, eds., Light a Candle. Encounters and Friendship with China, Monumenta Serica Institute, Sankt Augustin-Steyler Verlag, Nettetal, 2010.

Grupo de investigación sobre las misiones ibéricas en la época moderna, "Les politiques missionnaires sous le pontificat de Paul IV", Mélanges de l'École française de Rome, Italie et Méditerranée, 111-1999-1, 277-344.

Guerra, Alessandro, "Per un'archeologia della strategia missionaria dei Gesuiti: le indipetae e il sacrificio nella 'vigna del Signore", Archivio italiano per la storia della pietà, XIII, 2000, 109-191.

Guibert, Joseph de, s.J., La spiritualité de la Compagnie de Jésus, capítulo viI: "D’Aquaviva à Ricci (1615-1758), La vie spirituelle et les oeuvres de sanctification de la Compagnie", Rome, 1953, 277-278.

HsIA, Florence, Sojourners in a strange land: Jesuits and their scien- 
tific missions in late imperial China, Chicago, University of Chicago Press, 2009.

Huonder, Anton, Deutsche Jesuitenmissionäre des 17. Und 18. Jahrh., Fribourg, Herder'sche Verlagsbuchhandlung, 1899.

Imbruglia, Girolamo, "Ideali di civilizzazione: la Compagnia di Gesù e le missioni (1550-1600)", en Adriano Prosperi y Wolfgang Reinhard, Il Nuovo Mondo nella coscienza italiana e tedesca del Cinquecento, Bolońa, Il Mulino, 1992, 287-308.

Lamalle, Edmond, s.J., "La propagande du père Nicolas Trigault en faveur des misiones en Chine", Archivum Historicum Societatis Iesu, Ix, 1940, 49-120.

, "La documentation d'histoire missionnaire dans le 'Fondo Gesuitico' aux archives romaines de la Compagnie de Jésus”, Euntes Docete, xxI, 1968, 131-176.

, "Larchivio di un grande ordine religioso: l'Archivio Generale della Compagnia di Gesù", Archiva Ecclesiae, xxIv-xxv, 1, 1981-1982, 89-120.

Landry-Deron, Isabelle, "Les Mathématiciens envoyés en Chine par Louis XIV en 1685”, Archive for History of Exact Sciences, 555, 2001, 423-463.

, La preuve par la Chine. La "Description" de J. B. Du Halde, jésuite, 1735, París, Éditions de l'EHESS, 2002.

Leal de Barros, Mariana y Marina Massimi, "Releituras da indiferença: um estudo baseado em cartas de jesuitas dos sécalos XVI e XVII", Paidéia, 15(31), 2005, 195-205.

LeITÃo, Henrique, "A periphery between two centers? Portugal in the scientific route from Europe to China (16th and 17th centuries)", en Ana Simóes, Ana Carneiro, Maria Paula Diogo, eds., Travels of Learning. A Geography of Science in Europe, Dordrecht, Kluwer Academic Publishers, 2003, 19-46.

Leitão, Henrique, Luis Saraiva, "The College of São Paulo in Macao: A Background (16th and 17th Centuries)”, en Alan K. L. Chan, Gregory K. Clancey, Hui-Chieh Loy, Historical perspectives on East Asian Science, Technology and Medicine, Singapore, Singapore University Press, 2002.

McCoog, Thomas, s.J., A Guide to Jesuit Archives, St. Louis, Rome, 
The Institute of Jesuit Sources, Institutum Historicum Societatis Jesu, 2001.

Maldavsky, Aliocha, "Comment quitter l'Europe pour l'Amérique? Le mode d'emploi d'une quête missionnaire au début du XVIIe siècle", en Christian Buchet, dir., La Mer, la France et l'Amérique latine, París, PUPS, 2006, 149-166.

, "Administrer les vocations. Les Indipetae et l'organisation des expéditions de missionnaires aux Indes Occidentales au début du XVIIe siècle", en Bernard Vincent y Pierre-Antoine Fabre, ed., Notre lieu est le monde. Missions religieuses dans le monde ibérique à l'époque moderne, Roma, Ecole française de Rome, 2007, 45-70.

" "Société urbaine et désir de mission : les ressorts de la mobilité missionnaire jésuite à Milan au début du XVIIe siècle", Revue d'histoire moderne et contemporaine, julio-septiembre 2009, 7-32.

Marin, Catherine, "Passer sur l'autre rive: de l'Occident à l'Extrême-Orient", en Catherine Martin, Les écritures de la mission en Extrême-Orient. Le choc de l'arrivée, XVIIIe-XXe siècles: de l'attente à la réalité, Turnhout, Brepols, 2007, 17-107.

Massimi, Marina y André Barreto Prudente, Un encendido desejo das Índias, Saô Paolo, Ediçōes Loyola, 2002.

Massimi, Marina, "A 'Psicologia' dos Jesuítas: Uma Contribuição à História das Idéias Psicológicas", Psicologia, Reflexão e Crítica, 14 (3), 1999, 625-633.

Morineau, Michel, "Les jésuites parmi les hommes. La soif du martyre", en Les jésuites parmi les hommes aux XVIe et XVIIe siècles, Clermont-Ferrand, Publications de la Faculté des Lettres, 1987, 47-63.

NebGen, Christoph, '...dahin zillet mein verlangen und begierd.' Epistolae Indipetarum der Deutschen Assistenz der Gesellschaft Jesu als Quellengattung", en Johannes Meier, ed., Sendung-Eroberung-Begegnung. Franz Xaver, die Gesellschaft Jesu und die katholische Weltkirche im Zeitalter des Barock, Wiesbaden, Harrassowitz Verlag, 2005, 67-97.

, Missionarsberufungen nach Übersee in drei deutschen 
Provinzen der Gesellschaft Jesu im 17. und 18. Jahrhundert, Regensburg, Schnell \& Steiner, 2007.

Numhauser Bar-Magen, Paulina, "¿Sublevando el virreinato? Jesuitas italianos en el virreinato del Perú del siglo xvir. Gerónimo Pallas [s.I.]", en Laura Laurencich Minelli y Paulina Numhauser, ed., Sublevando el Virreinato. Documentos contestatarios a la historiografia tradicional del Perú colonial, Quito, Abya-Yala, 2007, 72-124.

Pacheco, Paulo Roberto de A., Liberdade indiferença: a "experiência-modelo" jesuitica em cartas de jovens indipetentes espan hóis dos séculos XVI e XVII, Tesis de doctorado en Psicología y Educación, Universidad de Sao Paulo, 2004.

Pacheco, Paulo Roberto de A. y Marina Massimi, "O conhecimento de si nas Litterae Indipetae", Estudos de Psicologia, vol. 10, núm. 3, septiembre-diciembre 2005, 345-354.

, "A experiência de "obediência" nas Indipetae", Memorandum, 17, 2009, 22-44.

, "The Experience of 'Consolation' in the Litterae Indiepetae", Psicologia em Estudo, Maringá, vol. 15, núm. 2, abril-junio 2010, 343-352.

Pizzorusso, Giovanni, "Le choix indifférent. Mentalités et attentes des jésuites aspirants missionnaires dans l'Amérique française au XVIIe siècle", Mélanges de l'École Française de Rome. Italie Méditerranée, tomo 10, 2-1997, 881-894.

"Autobiografia e vocazione in una littera indipeta del gesuita Pierre-Joseph-Marie Chaumonot, missionario in Canada (1637)", en Massimo Donattini, Giuseppe Marcocci, Stefania Pastore, ed., L'Europa divisa e i nuovi mondi. Per Adriano Prosperi, vol. II, Pisa, Edizioni della Normale, 2011, 191-200. (Publicación de la indipeta de Pierre Chaumonot, 1637)

Poumarède, Géraud, Pour en finir avec la Croisade: mythes et réalités de la lutte contre les Turcs aux XVIe et XVIIe siècles, París, PUF, 2004.

Prosperi, Adriano, “'Otras Indias': missionari della Controriforma tra contadini e selvaggi", Scienze credenze occulte livelli di cultura, Florencia, Olschki, 1982, 2035-234. 
, "L'Europa e il mondo: alle origini dell'idea di missione", Dimensioni e problemi della ricerca storica, 2, 1992, 189-220.

, Tribunali della coscienza, Turín, Einaudi, 1996.

RIcCI, Giovanni, L'ossessione turca. In una retrovia cristiana dell'Europa moderna, Boloña, Il Mulino, 2002.

, "Da Lepanto a Passarowitz. Echi dello scontro con gli Ottomani sulla religiosità e la cultura popolare in Italia", en Bernard Heyberger, Mercedes García-Arenal, Emanuele Colombo, Paola Vismara, Lislam visto da Occidente: cultura e religione del Seicento europeo di fronte allislam, Genova-Milán, 2009, 159-169.

Romano, Antonella, "Observer, vénérer, servir. Une polémique jésuite autour du Tribunal des mathématiques de Pékin”, Annales. Histoire, Sciences Sociales, 2004/4, 729-756.

, "Multiple identities, conflicting duties and fragmented pictures: the case of the Jesuits", en E. Oy-Marra y V. R. Remmert, Le monde est une peinture. Jesuitische Identität und die Rolle der Bilder, Berlín, Akademie Verlag, 2011, 45-69.

Roscioni, Gian Carlo, Il desiderio delle Indie. Storie, sogni e fughe di giovani gesuiti italiani, Turín, Einaudi, 2001.

Russell, Camila E., "Vocation to the East: Italian Jesuits Selected for the China Mission, 1590-1615", Renaissance Studies in Honor ofJoseph Connors, Florencia, L. S. Olschki, en prensa.

, "Imagining the "Indies": Italian Jesuit Petitions for the Overseas Missions at the Turn of the Seventeenth Century", en Massimo Donattini, Giuseppe Marcocci, Stefania Pastore, ed., L'Europa divisa e i nuovi mondi. Per Adriano Prosperi, vol. II, Pisa, Edizioni della Normale, 2011, 179-189.

Scaduto, Mario, Storia della Compagnia di Gesu in Italia, t. 3: L'epoca di Giacomo Lainez. Il governo 1556-1565, Roma, 1964.

Selwyn, Jennifer, D., A Paradise Inhabited by Devils: The Jesuits' Civilizing Mission in Early Modern Naples, Aldershot, Roma, Ashgate, IHSI, 2004.

SouzA, Laura V. y Marina Massimi, "Il desiderio dell'oltremare nelle litterae Indipetae: le condizioni psicologiche per l'azione nella narrativa di giovani gesuiti del sedicesimo secolo", Memorandum, 3, 2002, 55-71. 
Standaert, Nicolas, Handbook of christianity in China. T. I., 6351800, Leiden, Brill, 2001.

Taillandier, Marie-Françoise, Des réseaux français au service des missions lointaines, (1600-1663), Tésis de doctorado en Historia, Universidad de Clermont-Ferrand, 2003.

TurTas, Raimondo, "Primi risultati di una ricerca in corso: gli indipetae sardi tra il 1568 e il 1652", en Bruno Anatra y Giovanni Murgia, Sardegna, Spagna e Mediterraneo. Dai Re Cattolici al Secolo d'Oro, a cura di Roma 2004, 403-424.

, "Gesuiti sardi in terra di missione tra Seicento e Settecento", Bollettino di Studi Sardi, 2-2009. http://www.angelinotedde. com/2010/01/gesuiti-sardi-in-terra-di-missione-tra-seicento-e-se ttecento-di-raimondo-turtas/\#_ftn2

VAN DAMme, Stéphane, Le temple de la sagesse: savoirs, écriture et sociabilité urbaine: Lyon, XVIIe-XVIIIe siècle, París, Ediciones de la École des Hautes Études en Sciences Sociales, 2005.

VANTARD, Amélie, Les vocations pour les missions "ad gentes" (France, 1650-1750), Tésis de doctorado, Université du Maine, 2010.

, "Les vocations missionnaires chez les jésuites français aux XVIIle et XVIIIe siècles", Annales de Bretagne et des Pays de l'Ouest, 116-3, 2009, 9-22. 